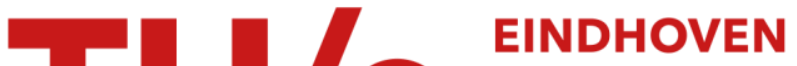 UNIVERSITY OF TECHNOLOGY
}

\section{Geometric connectivity analysis based on edge co- occurrences in retinal images}

Citation for published version (APA):

Abbasi-Sureshjani, S., Zhang, J., Sanguinetti, G. R., Duits, R., \& ter Haar Romenij, B. M. (2016). Geometric connectivity analysis based on edge co-occurrences in retinal images. 154-155. Abstract from 2016 Ophthalmic Medical Image Analysis Third International Workshop (OMIA 2016), Athens, Greece.

https://doi.org/10.17077/omia.1060

DOI:

10.17077/omia.1060

Document status and date:

Published: 01/10/2016

Document Version:

Publisher's PDF, also known as Version of Record (includes final page, issue and volume numbers)

Please check the document version of this publication:

- A submitted manuscript is the version of the article upon submission and before peer-review. There can be important differences between the submitted version and the official published version of record. People interested in the research are advised to contact the author for the final version of the publication, or visit the $\mathrm{DOI}$ to the publisher's website.

- The final author version and the galley proof are versions of the publication after peer review.

- The final published version features the final layout of the paper including the volume, issue and page numbers.

Link to publication

\section{General rights}

Copyright and moral rights for the publications made accessible in the public portal are retained by the authors and/or other copyright owners and it is a condition of accessing publications that users recognise and abide by the legal requirements associated with these rights.

- Users may download and print one copy of any publication from the public portal for the purpose of private study or research.

- You may not further distribute the material or use it for any profit-making activity or commercial gain

- You may freely distribute the URL identifying the publication in the public portal.

If the publication is distributed under the terms of Article $25 \mathrm{fa}$ of the Dutch Copyright Act, indicated by the "Taverne" license above, please follow below link for the End User Agreement:

www.tue.nl/taverne

Take down policy

If you believe that this document breaches copyright please contact us at:

openaccess@tue.nl

providing details and we will investigate your claim. 
Oct 21st, 2016

\section{Geometric Connectivity Analysis Based on Edge Co-Occurrences in Retinal Images}

Samaneh Abbasi-Sureshjani

Eindhoven University of Technology, The Netherlands

Jiong Zhang

Eindhoven University of Technology, The Netherlands

Gonzalo Sanguinetti

Eindhoven University of Technology, The Netherlands

Remco Duits

Eindhoven University of Technology, The Netherlands

Bart ter Haar Romeny

Eindhoven University of Technology, The Netherlands

Follow this and additional works at: http://ir.uiowa.edu/omia

Part of the Ophthalmology Commons

\section{Recommended Citation}

Abbasi-Sureshjani, Samaneh; Zhang, Jiong; Sanguinetti, Gonzalo; Duits, Remco; and Haar Romeny, Bart ter. Geometric Connectivity Analysis Based on Edge Co-Occurrences in Retinal Images. In: Chen X, Garvin MK, Liu J, Trucco E, Xu Y editors. Proceedings of the Ophthalmic Medical Image Analysis Third International Workshop, OMIA 2016, Held in Conjunction with MICCAI 2016, Athens, Greece, October 21, 2016. 154-155. Available from https://doi.org/10.17077/omia.1060

Rights

Copyright (C) 2016 the authors

Hosted by Iowa Research Online. For more information please contact: lib-ir@uiowa.edu. 


\title{
Geometric connectivity analysis based on edge co-occurrences in retinal images
}

\author{
Samaneh Abbasi-Sureshjani, Jiong Zhang, Gonzalo Sanguinetti, Remco Duits, \\ and Bart ter Haar Romeny \\ Eindhoven University of Technology, P.O. Box 513, 5600 MB, The Netherlands \\ \{s.abbasi, j.zhang1, r.duits, B.M.terhaarRomeny\}@tue.nl
}

\begin{abstract}
The network of tiny blood vessels in retinal images might be affected by several diseases such as diabetic retinopathy or hypertension. Analysis of the properties of this network is a classical source of rich diagnostic information. Several vessel segmentation and tracking techniques to automatically extract retinal vasculature biomarkers from retinal fundus images have been proposed in the literature. Tracking methods (such as graph-based techniques) to detect fully connected networks of blood vessels are often dependent on a proper initial vessel segmentation and skeleton extraction step. However, errors can easily propagate in the full tracking pipeline starting from segmentation, because of the presence of noise, low contrast regions, loss of information and interrupted vessel segments.

Junction points are key decision points during construction of the full vasculature network consisting of several tree-like structures. At these points, each tree either bifurcates to new branches or crosses other trees. The human brain is capable of grouping local edges into global contours remarkably easily. Inspired by this capability, a new method was proposed by [3] to distinguish the correct connections among the blood vessels at junction points. Contextual information is deployed in a similarity measurement approach based on the geometry of the primary visual cortex (V1) and further processed in a spectral clustering step for retrieving the individual perceptual units (blood vessels) from segmentations. By creating a $3 \mathrm{D}$ representation of a $2 \mathrm{D}$ image in a coupled space of positions and orientations using the orientation score transformation [2], crossing elongated structures in retinal images were disentangled from each other. The cortical connectivity in this lifted domain was modelled stochastically (using the Markov Chain Monte-Carlo method [5]) by the fundamental solution of the timeindependent Fokker-Planck equation for Mumford's direction process [4]. There exist various numerical approximations, and exact solutions for this equation. For a recent and complete comparison see [8] and the references therein.

In [6] it is shown that there is a close relation between the statistics of edge co-occurrence in natural images and the contour perception problem. In this work, we propose to learn the kernel from retinal images and use this statistical kernel directly in connectivity analysis. In order to obtain the edge co-occurrence (considered as the statistical kernel), the retinal images are lifted to the coupled
\end{abstract}

X. Chen, M. K. Garvin, J. Liu, E. Trucco, Y. Xu (Eds.): OMIA 2016, Held in Conjunction with MICCAI 2016, Athens, Greece, Iowa Research Online, pp. 154-155, 2016. Available from: http://ir.uiowa.edu/omia/2016_Proceedings/2016/ 
space of positions and ( $\pi$-periodic) orientations in $\mathbb{R}^{2} \times P^{1}$. Using this information and by the assumption of translation invariance, a $4 \mathrm{D}$ histogram in $\mathbb{R}^{2} \times P^{2}$ is obtained by finding the cross-correlation histogram of relative positions and orientations of vessel centerline points. Then by assuming the rotation-invariance property, the relative positions are rotated using the relative orientations and the $4 \mathrm{D}$ histogram is converted to a $3 \mathrm{D}$ kernel of rotated positions and relative orientations. This so-called data-driven kernel has been created for two different public datasets having different pixel sizes and resolutions. The vessel centerlines are created by thinning the vessel segmentations.

These data-driven kernels are compared with each other and the $l_{2}$-norms of their differences are obtained. The obtained results show that the kernels have very similar characteristics and their mutual differences are less than $2 \%$. Therefore, they can be used interchangeably. In another step, each statistical kernel is compared against a set of solutions of the Fokker-Planck equation obtained using a Fourier-based technique [1] varying its parameters. Then we obtain the parameters of the best numerical approximations of the data-driven kernels which result in the least squared errors (less than $1 \%$ for both datasets). These parameters are very close to the ones used for creation of the stochastic kernel in [3], which were found heuristically. Furthermore, we could make the vessel connectivity analysis technique fully automatic by using not only the data-driven kernel as the cortical connectivity model, but also by exploiting a self-tuning spectral clustering technique [7] for detecting individual blood vessels based on the affinity matrix. This connectivity analysis can be further used in the creation of a model of the entire retinal vasculature and analysis of its properties. Moreover, the same approach can be used in parameter tuning of perceptual completion tasks.

\section{References}

1. August, J.M.: The curve indicator random field. Ph.D. thesis, Yale University (2001)

2. Duits, R., et al: Image analysis and reconstruction using a wavelet transform constructed from a reducible representation of the Euclidean motion group. IJCV 72(1), 79-102 (2007)

3. Favali, M., et al: Analysis of vessel connectivities in retinal images by cortically inspired spectral clustering. JMIV 56(1), 158-172 (2016)

4. Mumford, D.: Elastica and computer vision, chap. Algebraic Geometry and its Applications, pp. 491-506. Springer New York (1994)

5. Robert, C., Casella, G.: Monte Carlo statistical methods. Springer Science \&amp; Business Media (2013)

6. Sanguinetti, G., et al: A model of natural image edge co-occurrence in the rototranslation group. J. Vis. 10(14), 37 (2010)

7. Zelnik-Manor, L., et al: Self-tuning spectral clustering. In: NIPS. pp. 1601-1608. MIT Press (2004)

8. Zhang, J., et al: Numerical approaches for linear left-invariant diffusions on SE(2), their comparison to exact solutions, and their applications in retinal imaging. NMTMA 9, 1-50 (2016) 